\title{
A Simple Clinical Guide for Health Care Students to Assess and Plan for Care at Two Teaching Hospitals in Kigali, Rwanda
}

\author{
Priscille Musabirema ${ }^{1}$; Rondi Anderson ${ }^{2}$ \\ ${ }^{1}$ University of Rwanda, School of Nursing and Midwifery, \\ ${ }^{2}$ Mubima Hospital in Kigali, Rwanda
}

\section{Background}

In the late summer of 2013 it was noted that healthcare professional students in Rwanda had certain gaps in their ability to obtain a complete history, physical exam and to make a diagnosis and a plan. It was a problem identified in both students and staff, that doing a thorough presentation of a patient's situation was difficult and often inadequate.

\section{Description}

A group of nursing students from the then Kigali Health Institute were directed to prepare a guide that could be used to assist students doing patient assessments. Three guides were made in the fall, one for an admission assessment with focus on a pregnant woman, one for post-partum, and one for newborn. In the fall of 2013 these guides were used with nursing and midwifery students at the maternity department of CHUK the teaching hospital in Kigali. In the winter of 2014 their use was expanded to Muhima hospital and to include medical students. Since then they are being used by all students at Muhima hospital.

The reception of the guide has been quite positive. Positive feedback has been received from over one hundred students who have used the guide. The students stated that it helped them to approach the patient and knew what questions to ask. They also commented that they discovered things about the patients that they would have otherwise not known. The students themselves requested the guide and wanted to share it with other students. Clinical faculty stated that they found that these guides were quite helpful in that the students' ability to present the patient had improved dramatically. The clinical faculty also found that using this guide helped them to give the students daily feedback and students were then improving their knowledge and skills more effectively.

\section{Lessons Learned}

Students ability to perform well clinically can be vastly improved with a simple guide. There is some minimal cost in reproducing the guide. Students still need support even when using the guide to gain confidence and skill.

\section{Conclusion}

Future challenges are to involve more midwifery and nursing staff, and help them to strengthen their ability to do assessments and communicate a thorough patient history to other colleagues including medical staff.

Key words: patient history, physical exam, diagnosis, guide, patient assessments, daily feedback 